\title{
Co-Occurrence of Acromegaly and Hematological Disorders: A Myth or Common Pathogenic Mechanism?
}

\author{
Prakamya Gupta ${ }^{a}$ Pinaki Duttab \\ Departments of a Neurosurgery and ${ }^{b}$ Endocrinology, Postgraduate Institute of Medical \\ Education and Research, Chandigarh, India
}

Keywords

Acromegaly $\cdot$ Leukemia $\cdot$ Hematological disorders

\begin{abstract}
Background: Acromegaly is not one disease but an association of clinical, biochemical and radiological features. Altered blood counts are often observed in acromegaly patients. Acromegaly patients presenting with a hematological malignancy are rare. To date, there are several cases that have reported the co-occurrence of these diseases. Summary: The coexistence of the two diseases can be a mere coincidence or may have a common pathogenic mechanism. The rarity of these conditions and the small number of patients makes it difficult to determine the real role of elevated growth hormone and insulin-like growth factor-1 levels in the occurrence of hematological malignancies. Patients with growth hormone $(\mathrm{GH})$ replacement due to $\mathrm{GH}$-deficient acromegaly are at a high risk of developing hematological disorders. Conclusion: In this review, we aim to provide evidence for the correlation between the two disorders.

(C) 2017 The Author(s)

Published by S. Karger AG, Basel
\end{abstract}

\section{Introduction}

Acromegaly is caused by growth hormone (GH)-producing pituitary adenoma. The annual incidence of acromegaly is 3 per million and the prevalence 40 per million; thus, it is a relatively rare disease [1,2]. Although benign, intracranial neoplasia can cause significant morbidity and mortality. In the last century, acromegaly presenting with hematological malignancies was

Dr. Pinaki Dutta

Department of Endocrinology

Postgraduate Institute of Medical Education and Research

Chandigarh 160012 (India)

E-Mail Pinaki_dutta@ hotmail.com 
Table 1. Coexistence of acromegaly and hematological disorders

\begin{tabular}{lllll}
\hline Year & $\begin{array}{l}\text { Age/ } \\
\text { gender }\end{array}$ & $\begin{array}{l}\text { Pituitary } \\
\text { adenoma subtype }\end{array}$ & Hematological disorders & Reference \\
\hline 1996 & $41 / \mathrm{F}$ & Acromegaly & Promyelocytic leukemia & 43 \\
1996 & $42 / \mathrm{M}$ & Acromegaly & Polycythemia vera & 44 \\
1998 & $57 / \mathrm{M}$ & Acromegaly & Non-Hodgkin lymphoma & 45 \\
2000 & $57 / \mathrm{F}$ & Acromegaly & Non-Hodgkin lymphoma & 30 \\
2000 & $33 / \mathrm{F}$ & Acromegaly & Acute leukemia & 46 \\
2002 & $63 / \mathrm{M}$ & Acromegaly & CML & 34 \\
2006 & $65 / \mathrm{F}$ & Acromegaly & MGUS & 47 \\
2009 & $61 / \mathrm{M}$ & Acromegaly & Acute lymphoblastic leukemia & 48 \\
2011 & $59 / \mathrm{F}$ & Acromegaly & Multiple myeloma & 49 \\
2011 & $60 / \mathrm{F}$ & Acromegaly & Waldenstrom macroglobulinemia & 49 \\
2012 & $43 / \mathrm{M}$ & Acromegaly & Polycythemia vera & 50 \\
2012 & $72 / \mathrm{M}$ & Acromegaly & Primary thrombocythemia & 21 \\
2013 & $70 / \mathrm{M}$ & Acromegaly & AML & 51 \\
2015 & $58 / \mathrm{F}$ & Acromegaly & Multiple myeloma & 52 \\
\hline
\end{tabular}

AML, acute myeloid leukemia; CML, chronic myeloid leukemia; MGUS, monoclonal gammopathy of undetermined significance.

sparsely reported in the literature, mostly as case reports. To date, several hematological malignancies such as polycythemia vera, essential thrombocytosis, chronic myeloid leukemia (CML), thrombocytopenia, or Hodgkin lymphoma have been reported in patients with pituitary adenoma, mainly in acromegaly patients (Table 1). The coexistence of the two diseases can be a mere coincidence or a common pathogenic mechanism. The rarity of these conditions and the small number of patients makes it difficult to determine the real role of elevated GH and insulinlike growth factor-1 (IGF-1) levels in the occurrence of hematological malignancies. Although the data are insufficient to claim that there is a correlation between acromegaly and hematological malignancies, the existence of such a relationship cannot be ruled out. Whether GH therapy increases the risk of leukemia and solid tumors is controversial. Current data indicate that any increased risk of leukemia is limited to children with underlying conditions that already predispose them to develop malignancies $[3,4]$. In this short review, we concentrate on the existing knowledge of the genetic background of both acromegaly and leukemia to provide some evidence for the correlation between these disorders.

\section{Not All Acromegaly Patients Have Leukemia}

It is one of the rarest phenomena that acromegaly patients manifest hematological disorders. However, altered hematological parameters are often observed in acromegaly patients. A study by Arpaci et al. [5] has shown that the mean platelet volume is higher in acromegaly patients compared to controls of the same age and gender. Acromegaly patients are prone to morbidity and mortality caused by cardiovascular, respiratory, and cerebrovascular diseases and malignancies. These diseases are often associated with chronic inflammation. The neutrophil to lymphocyte ratio and platelet to lymphocyte ratio are good markers for inflammation. In their study, Üçler et al. [6] demonstrated that there exists a significant positive correlation between the neutrophil to lymphocyte ratio and IGF-1 levels $(p=0.011)$ as well as between the platelet to lymphocyte ratio and IGF-1 $(p=0.035)$. Acromegaly patients show significant fibrinogen and antithrombin activity, thereby showing an increased tendency to coagulation and enhanced 


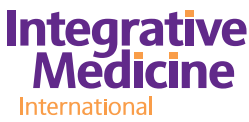

Integrative
Medicine

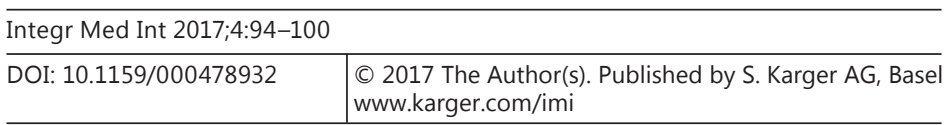

www.karger.com/imi

Guptaa and Duttab: Co-Occurrence of Acromegaly and Hematological Disorders: A Myth or Common Pathogenic Mechanism?

platelet aggregability [7]. This hypercoagulable state increases the risk for cardiovascular and cerebrovascular events in acromegaly. Furthermore, there is experimental evidence which shows that endogenous GH hypersecretion is responsible for the reversible plasma volume and red blood cell volume increases, frequently found in acromegaly patients [8].

\section{GH Treatment and Risk of Leukemia}

GH deficiency (GHD) is characterized by abnormal body composition, cardiovascular risk, decreased muscle strength, reduced bone density, and impaired quality of life. Deficiency of GH still remains the major cause of morbidity and mortality in pediatric patients. GHD is one of the most common complications in acromegaly patients treated with multiple modalities [9]. The administration of recombinant human GH to these patients was shown to reverse many of the abnormalities [10]. However, a positive correlation between GH therapy and increased risk of leukemia was first reported in 1988 in Japan [11]. Further studies reported an occurrence of leukemia in children treated with GH [12-15]. Survivors of childhood leukemia are at risk of developing growth failure, thus requiring GH treatment. Treating children with GH after therapy for leukemia may therefore cause a higher risk of leukemia recurrence. These studies clearly demonstrate a crosstalk between the GH/IGF-1 pathway and leukemia. The onset of leukemia is associated with hemostatic derangement favoring hypercoagulability. The coagulopathy is due to thrombin activation. Our previous results have demonstrated that acromegaly patients with GHD who were treated with recombinant GH showed increase activity of plasminogen activator inhibitor-1; however, our study was too short to examine the risk of leukemia [16].

\section{Genetic Alteration and Signal Transduction in Acromegaly and Leukemia}

Modern technology in genome and exome sequencing identified several genetic alterations in genes involved in GH producing pituitary adenomas. Indeed, mutations in the genes GNAS, AIP, MEN1, CDKN1B, PRKARIA, SDHX, and GPR101 were identified to result in somatotropinoma (or acromegaly) and rarely pituitary hyperplasia. Activating mutations in one of the genes, GNAS, are well known to play a role in the pathogenesis of somatotropinomas [17]. In $95 \%$ of the cases, it occurs sporadically but they are present in almost $50 \%$ of childhood onset. Also germline mutations in the AIP, MEN1, and GPR101 genes (e.g., by microduplication) account for the cases of familial isolated pituitary adenomas [18].

The discovery of the breakpoint cluster region and cABL (BCR-ABL1) fusion tyrosine kinase as the direct cause of CML led to the development of the drug imatinib mesylate. The BCR-ABL fusion activates many signaling pathways such as the JAK-STAT pathway, the PI3K/ AKT/mTOR pathway, or the RAS/RAF/MAP kinase pathway. Activation of the JAK-STAT pathway results in increased proliferation of myeloid cells. Furthermore, the discovery of somatic activating mutations in the JAK2 tyrosine kinase in 2005 shed new light into the pathogenesis of the Philadelphia-negative myeloproliferative disorders [19]. Acute myeloid leukemia (AML) with a normal karyotype accounts for approximately $40-50 \%$ of adult and $25 \%$ of pediatric patients and is composed of a heterogeneous group with an intermediate prognosis. The growth hormone actions are also mediated via the GH receptor and their interaction results in the phosphorylation of JAK2 with subsequent phosphorylation of downstream STATs, thereby leading to the activation of the Ras/MAP kinase pathway [20]. Ciresi et al. [21] have reported a unique case of acromegaly due to GH-secreting pituitary adenoma associated with JAK2 V617F mutation. Since the signaling by the mutated kinase utilizes normal pathways, this results in an overproduction of morphologically normal blood cells, an often indolent course 
and usually a normal lifespan. It is speculated that elevated GH and IGF-1 could behave as myeloid co-stimulating factors, in concomitance with erythropoietin. Of interest, both erythropoietin and GH are known to activate gene transcription through the JAK2/STAT signaling cascade [22]. These hormones, acting as chronic stimuli, may trigger the development and selection of myeloid progenitors characterized by faster growth kinetics in a GH-rich environment. However, they still stop proliferating after withdrawal of the chronic stimulus. The clones growing in the absence of GH might result in a full-blown myeloproliferative disorder.

\section{Overlapping Signaling Pathways in Pituitary Adenoma and Leukemia}

The mechanisms underlying leukemogenesis and pituitary adenomas involve changes in common cellular signaling pathways. Increased expression of pituitary tumor transforming gene 1 (PTTG1) was extensively studied in pituitary adenomas including somatotropinoma, as well as a neoplastic transformation in a wide range of cell types [23]. Moreover, PTTG1 gene was reportedly overexpressed in multiple myeloma [24]. The knockdown of PTTG1 significantly inhibited the proliferation of myeloma cells in vitro, with an associated decrease in the expression of mitosis-related genes, and slowed tumor development in vivo. Indeed, expression of PTTG1 was previously noted in gene expression signatures defining myeloma patients with highly proliferative disease and chromosomal instability. In summary, these data suggest that the poor prognosis associated with PTTG1 expression is due to a hyperproliferative state in these patients, which may result from the PTTG1-mediated upregulation of key drivers of cell cycle progression [24]. Similarly, leukemia inhibitory factor, a pleiotropic, neuropoietic cytokine that affects cell growth by inhibiting differentiation, is found to be expressed on somatotropinomas [25]. Leukemia inhibitory factor acts as a critical molecular interface between the neuroimmune and endocrine systems [26].

The mechanisms underlying leukemogenesis often involve changes in cellular signaling, which can inhibit hematopoietic progenitor cells from: (i) responding to normal signals regulating proliferation and/or (ii) differentiating into mature red blood cells, monocytes, neutrophils, and platelets [14]. Many pathways were attested to be altered in AML blood and bone marrow cells, including the nuclear factor kappa-light-chain-enhancer of activated B cells (NF- $\mathrm{B}$ ) [13], mitogen-activated protein kinase, and Wnt/ $\beta$-catenin pathways [17]. The aryl hydrocarbon receptor $(A h R)$ pathway is also implicated in leukemogenesis, where, for example, primary human T-cell leukemia cells exhibit upregulated $A h R$ expression and activation. Furthermore, mis-regulated $A h R$ signaling within hematopoietic stem cells was proposed as a possible mechanism linking benzene exposure to AML development [27]. The $A h R$ protein complex connects leukemia and somatotropinoma. Altered $A h R$ expression and activity was described in human leukemia and lymphoma cells. The $A h R$ gene is epigenetically regulated with a high level of promoter methylation in acute lymphoblastic leukemia, chronic myeloid leukemia and K562 cell line $[15,28]$. The aryl hydrocarbon interacting protein (AIP) is a co-chaperone that forms the AIP-AhR-Hsp90 complex and plays a very important role in the pathogenesis of somatotropinomas. In fact, $A I P$ is one of the genes identified with some cases of sporadic somatotropinoma.

\section{GH and GH Receptor Expression Impacts Immune Cells}

It is intriguing to speculate on whether overexpression of GH is important for the maintenance and/or the development of these different types of leukemia and lymphoma or whether it results in a constitutive activation of NF- $\mathrm{BB}$. The NF- $\mathrm{BB}$ is a protein complex 
involved in DNA regulation and different cellular responses [29]. Constitutive activation of $\mathrm{NF}-\kappa \mathrm{B}$ affects the development and progression of a wide range of cancers, including Hodgkin lymphoma, B cell lymphoma, and T cell leukemia/lymphoma. Conversely, a single case report of ectopic secretion of GH from a non-Hodgkin lymphoma has been documented in the literature. Whether there is a common pathogenetic mechanism is not known [30]. The possibility that GH participates in promoting immune cell tumors or autoimmune diseases via the constitutive activation of NF- $\mathrm{BB}$ warrants further investigations [31-33].

The crosstalk between the immune and neuroendocrine system is a well-known entity. These systems use similar ligands and receptors to establish a physiological intra- and intersystem communication circuitry that plays an important role in homeostasis. Increasing evidence indicates that hormones and neuropeptides are potent immunomodulators, participating in various aspects of immune system function in both healthy individuals and during disease. Also, GH plays an important role in immunity. This is supported by in vitro and animal data in a study by Murphy et al. [34] who reported that the administration of GH stimulated hematopoietic stem cells and caused lymphoid malignancies in murine models. Also Hattori et al. [35] reported a widespread distribution of ghrelin and GH secretagogue receptor in human immune cells. However, the biological functions other than enhancing GH secretion in the immune system still remain unknown. Also, exogenous GH administration enhances IgG production by B cells [36].

\section{Treatment of CML and Inhibition of the GH/IGF-1 System}

Due to the rare combination, it is still unclear which disease should be given priority in terms of treatment. Imatinib is a protein tyrosine kinase inhibitor (TKI) developed to target the gene product of the Philadelphia chromosome (Bcr/Abl) translocation in CML [37]. Imatinib is currently approved for the first-line treatment of CML and gastrointestinal stromal tumor [38]. It is a potent and selective inhibitor of protein tyrosine kinases such as PDGFR- $\alpha$ and PDGFR- $\beta$, Bcr-Abl, VEGF and c-Kit, all of which are also expressed in pituitary adenomas [39]. A study by Lara-Castillo et al. [40] have demonstrated that bromocriptine, an approved drug originally indicated for Parkinson disease, acromegaly, hyperprolactinemia, and galactorrhea, showed reduced cell viability of AML cells by activation of the apoptosis program and induction of myeloid differentiation indicating crosstalk between hematopoietic and pituitary cells. A few isolated reports mentioned successful use of TKIs for the treatment of pituitary adenoma. Also, our in vitro study in cultured somatotropinoma and GH3 cells has demonstrated that imatinib inhibits the GH/IGF-1 axis and re-emphasizes the crosstalk [41, 42]. In future, TKIs could be the choice of treatment for patients with acromegaly and hematological disorders. However, long-term controlled clinical trials are required to establish TKI as a treatment modality for these patients before any recommendation can be made.

\section{Conclusion}

Though the incidence of co-occurrence of acromegaly and leukemia is a rare phenomenon, acromegaly patients are prone to develop several hematological disorders. Acromegaly patients (especially childhood acrogiants) with GHD who have been treated with recombinant GH are probably at a modest risk of occurrence of leukemia or other cancer types. Therefore, in conclusion, a complete hemogram is recommended in all acromegaly patients during diagnostic workup as well as at regular follow-up. Large-scale epidemiological studies are required to predict the incidence and prevalence of the disease. The coexistence of the 
Guptaa and Duttab: Co-Occurrence of Acromegaly and Hematological Disorders: A Myth or Common Pathogenic Mechanism?

two diseases can only be explained by whole exome/genome sequencing which may shed light into the pathophysiology of the disease. Imatinib could be a choice of treatment for concurrent acromegaly and myeloproliferative disorder.

\section{Disclosure Statement}

The authors have no conflicts of interest to declare and have contributed equally.

\section{References}

1 Ezzat S, Forster MJ, Berchtold P, Redelmeier DA, Boerlin V, Harris AG: Acromegaly. Clinical and biochemical features in 500 patients. Medicine (Baltimore) 1994;73:233-240.

-2 Fernandez A, Karavitaki N, Wass JA: Prevalence of pituitary adenomas: a community-based, cross-sectional study in Banbury (Oxfordshire, UK). Clin Endocrinol (Oxf) 2010;72:377-382.

-3 Wilson TA, Rose SR, Cohen P, Rogol AD, Backeljauw P, Brown R, etal: Update of guidelines for the use of growth hormone in children: the Lawson Wilkins Pediatric Endocrinology Society Drug and Therapeutics Committee. J Pediatr 2003;143:415-421.

-4 Swerdlow AJ, Cooke R, Beckers D, Borgstrom B, Butler G, Carel JC, et al: Cancer risks in patients treated with growth hormone in childhood: the SAGhE European Cohort Study. J Clin Endocrinol Metab 2017;102:16611672.

5 Arpaci D, Kuzu F, Unal M, Ilikhan SU, Buyukuysal MC, Bayraktaroglu T: Assessment of mean platelet volume and its effect on disease control in patients with acromegaly. Clin Lab 2016;62:2167-2171.

-6 Üçler R, Aslan M, Atmaca M, Alay M, Ademoglu EN, Gulsen I: Evaluation of blood neutrophil to lymphocyte and platelet to lymphocyte ratios according to plasma glucose status and serum insulin-like growth factor 1 levels in patients with acromegaly. Hum Exp Toxicol 2016;35:608-612.

7 Colak A, Yilmaz H, Temel Y, Demirpence M, Simsek N, Karademirci I, et al: Coagulation parameters and platelet function analysis in patients with acromegaly. J Endocrinol Invest 2016;39:97-101.

$\checkmark 8$ Strauch G, Lego A, Therain F, Bricaire H: Reversible plasma and red blood cells volumes increases in acromegaly. Acta Endocrinol 1977;85:465-478.

$\checkmark 9$ Melmed S, Casanueva FF, Klibanski A, Bronstein MD, Chanson P, Lamberts SW, et al: A consensus on the diagnosis and treatment of acromegaly complications. Pituitary 2013;16:294-302.

10 Miller KK, Wexler T, Fazeli P, Gunnell L, Graham GJ, Beauregard C, et al: Growth hormone deficiency after treatment of acromegaly: a randomized, placebo-controlled study of growth hormone replacement. J Clin Endocrinol Metab 2010;95:567-577.

11 Leukaemia in patients treated with growth hormone. Lancet 1988;1:1159-1160.

12 Fradkin JE, Mills JL, Schonberger LB, Wysowski DK, Thomson R, Durako SJ, et al: Risk of leukemia after treatment with pituitary growth hormone. JAMA 1993;270:2829-2832.

13 Watanabe S, Mizuno S, Oshima LH, Tsunematsu Y, Fujimoto J, Komiyama A: Leukemia and other malignancies among GH users. J Pediatr Endocrinol 1993;6:99-108.

14 Nishi Y, Tanaka T, Takano K, Fujieda K, Igarashi Y, Hanew K, et al: Recent status in the occurrence of leukemia in growth hormone-treated patients in Japan. GH Treatment Study Committee of the Foundation for Growth Science, Japan. J Clin Endocrinol Metab 1999;84:1961-1965.

-15 Hayashibara T, Yamada Y, Mori N, Harasawa H, Sugahara K, Miyanishi T, et al: Possible involvement of aryl hydrocarbon receptor (AhR) in adult T-cell leukemia (ATL) leukemogenesis: constitutive activation of AhR in ATL. Biochem Biophys Res Commun 2003;300:128-134.

16 Dutta P, Mahendran B, Reddy KS, Ahluwalia J, Vaiphei K, Kochhar RK, et al: Short-term efficacy of recombinant human GH therapy in cured acromegaly patients with GH deficiency: a single-center experience. Endocr Connect 2015;4:65-75.

17 Gadelha MR, Kasuki L, Korbonits M: The genetic background of acromegaly. Pituitary 2017;20:10-21.

18 Trivellin G, Daly AF, Faucz FR, Yuan B, Rostomyan L, Larco DO, et al: Gigantism and acromegaly due to Xq26 microduplications and GPR101 mutation. N Engl J Med 2014;371:2363-2374.

19 James C, Ugo V, Le Couedic JP, Staerk J, Delhommeau F, Lacout C, et al: A unique clonal JAK2 mutation leading to constitutive signalling causes polycythaemia vera. Nature 2005;434:1144-1148.

-20 Argetsinger LS, Campbell GS, Yang X, Witthuhn BA, Silvennoinen O, Ihle JN, et al: Identification of JAK2 as a growth hormone receptor-associated tyrosine kinase. Cell 1993;74:237-244.

21 Ciresi A, Guarnotta V, Tomasello L, Calo V, Russo A, Galluzzo A, et al: Janus kinase (JAK) 2 V617F mutation as the cause of primary thrombocythemia in acromegaly with severe visceromegaly and divergence between growth hormone and insulin-like growth factor-1 concentrations during the follow-up: causal or casual association? Growth Horm IGF Res 2012;22:92-96. 
$-22$

23

$>24$

$>25$

$-26$

\section{Endocr Rev 2000;21:313-345.}

-27 Rager JE, Fry RC: The aryl hydrocarbon receptor pathway: a key component of the microRNA-mediated AML signalisome. Int J Environ Res Public Health 2012;9:1939-1953.

-28 Mulero-Navarro S, Carvajal-Gonzalez JM, Herranz M, Ballestar E, Fraga MF, Ropero S, et al: The dioxin receptor is silenced by promoter hypermethylation in human acute lymphoblastic leukemia through inhibition of Sp1 binding. Carcinogenesis 2006;27:1099-1104.

29 Pahl HL: Activators and target genes of Rel/NF-kappaB transcription factors. Oncogene 1999;18:6853-6866. , Strasburger CJ, Siegerstetter V, Moradpour D, Lichter P, Bidlingmaier M, et al: Acromegaly caused by secretion of growth hormone by a non-Hodgkin's lymphoma. N Engl J Med 2000;342:1871-1876.

-31 Bargou RC, Emmerich F, Krappmann D, Bommert K, Mapara MY, Arnold W, et al: Constitutive nuclear factor-kappaB-RelA activation is required for proliferation and survival of Hodgkin's disease tumor cells. J Clin Invest 1997; 100:2961-2969.

-32 Bellavia D, Campese AF, Alesse E, Vacca A, Felli MP, Balestri A, et al: Constitutive activation of NF-kappaB and T-cell leukemia/lymphoma in Notch3 transgenic mice. EMBO J 2000;19:3337-3348.

-33 Guzman ML, Neering SJ, Upchurch D, Grimes B, Howard DS, Rizzieri DA, et al: Nuclear factor-kappaB is constitutively activated in primitive human acute myelogenous leukemia cells. Blood 2001;98:2301-2307.

34 Murphy PT, Ahmed N, Hassan HT: Chronic myeloid leukemia and acromegaly in POEMS syndrome. Leuk Res 2002;26:1135-1137.

-35 Hattori N, Saito T, Yagyu T, Jiang BH, Kitagawa K, Inagaki C: GH, GH receptor, GH secretagogue receptor, and ghrelin expression in human T cells, B cells, and neutrophils. J Clin Endocrinol Metab 2001;86:4284-4291.

-36 Yoshida A, Ishioka C, Kimata H, Mikawa H: Recombinant human growth hormone stimulates B cell immunoglobulin synthesis and proliferation in serum-free medium. Acta Endocrinol (Copenh) 1992;126:524-529.

-37 Cortes J, Goldman JM, Hughes T: Current issues in chronic myeloid leukemia: monitoring, resistance, and functional cure. J Natl Compr Canc Netw 2012;10(suppl 3):S1-S13.

-38 Jabbour E, Kantarjian H: Chronic myeloid leukemia: 2012 update on diagnosis, monitoring, and management. Am J Hematol 2012;87:1037-1045.

-39 Danial NN, Rothman P: JAK-STAT signaling activated by Abl oncogenes. Oncogene 2000;19:2523-2531.

-40 Lara-Castillo MC, Cornet-Masana JM, Etxabe A, Banus-Mulet A, Torrente MA, Nomdedeu M, et al: Repositioning of bromocriptine for treatment of acute myeloid leukemia. J Transl Med 2016;14:261.

-41 Narayanan KR, Bansal D, Walia R, Sachdeva N, Bhansali A, Varma N, et al: Growth failure in children with chronic myeloid leukemia receiving imatinib is due to disruption of GH/IGF-1 axis. Pediatr Blood Cancer 2013; 60:1148-1153.

-42 Prakamya Gupta AR, Naresh Sachdeva, Bishan Das Radotra, Anil Bhansali, Kanchan Kumar Mukherjee, Debashish Hota, Márta Korbonits, Pinaki Dutta: In vitro effects of imatinib on somatotrophinoma cell line. Endocr Abstracts 2015:38:305.

43 Beyan C, Ural AU, Cetin T, Ozata M, Yalcin A: Acute promyelocytic leukemia in the course of acromegaly: a case report. Endocr J 1996;43:565-568.

44 Grellier P, Chanson P, Casadevall N, Abboud S, Schaison G: Remission of polycythemia vera after surgical cure of acromegaly. Ann Intern Med 1996;124:495-496.

45 Alves RH, Vaisman M, Brasil RR, Gadelha MR: Acromegaly and non-Hodgkin's lymphoma. Endocr Pract 1998; $4: 279-281$.

-46 Au WY, Chow WS, Lam KS, Ko GT, Cockram CS, Kwong YL: Acute leukaemia in acromegaly patients. Br J Haematol 2000;110:871-873.

47 Kanazawa I, Yamaguchi T, Yamane Y, Murakami N, Kato Y, Sugimoto T: Acromegaly associated with monoclonal gammopathy of undetermined significance (MGUS). Endocr J 2006;53:687-691.

48 Adib MH, Ebadi A: Acromegaly associated with leukemia: a case report. Int J Endocrinol Metab 2009;1:46-50.

49 Barbosa FR, Vieira Neto L, Lima GA, Wildemberg LE, Portugal R, Gadelha MR: Hematologic neoplasias and acromegaly. Pituitary 2011;14:377-381.

-50 Zoppoli G, Bianchi F, Bruzzone A, Calvia A, Oneto C, Passalia C, Balleari E, Bedognetti D, Ponomareva E, Nazzari E, Castelletti L, Castellan L, Minuto F, Ghio R, Ferone D: Polycythemia as rare secondary direct manifestation of acromegaly: management and single-centre epidemiological data. Pituitary 2012;15:209-214.

51 Ozeki K, Morishita Y, Saito S, Umemura K, Yamaguchi Y, Tatekawa S, Watamoto K, Kohno A, Nogimori T: Acute myeloid leukemia and colon carcinoma during the course of acromegaly. Int J Hematol 2013;98:620-624.

-52 Kang YM, Choi JH, Lee MJ, Ahn A, Park CJ, Chang K, Seo S, Hong SI, Kim MS: Multiple myeloma in a patient with acromegaly. Endocrinol Metab (Seoul) 2015;30:110-115. 